\title{
Chloroplast and Nuclear Genome Analysis of the Parentage of Lemons
}

\author{
O. Gulsen ${ }^{1}$ and M.L. Roose ${ }^{2}$ \\ Department of Botany and Plant Sciences, University of California, Riverside, CA 92521
}

\begin{abstract}
AdDitional INDEX words. Citrus limon, inter-simple sequence repeat, isozyme, simple sequence repeat, restriction fragment length polymorphism, genetic diversity

Abstract. Chloroplast DNA (cpDNA) restriction fragment length polymorphisms were used to study the parentage of lemons [Citrus limon (L.) Burm. f.] and several other putative hybrids. The 30 citrus accessions studied included nine lemons, three pummelos [C. maxima (Burm.) Merrill], three citrons (C. medica L.), three mandarins $(C$. reticulata Blanco, C. clementina Hort. Ex. Y. Tan., and $C$. sunki Hort. ex. Tan.), and single representatives of 13 other taxa. Four different fragments of citrus cpDNA were amplified by polymerase chain reaction using four universal chloroplast primers and amplification products were digested with four endonucleases, Rsa I, Dra I, Hae III, and Mbo I. A total of 104 different restriction fragments were scored and used for phylogenetic analysis by parsimony. The three taxa which have been proposed as ancestral Citrus L. sp., $C$. medica, $C$. maxima, and $C$. reticulata, had distinct cpDNA patterns. Pummelo contributed the chloroplast genome to lemons, sweet orange [C. sinensis $(\mathrm{L}$.) Osbeck], and Bergamot orange $(C$. bergamia Risso and Poit.), and mandarin contributed the chloroplast genome to rough lemons (C. jambhiri Lush.), Rangpur lime (C. limonia Osbeck), and 'Mexican' lime [C. aurantifolia (Christm.) Swing.]. Data suggest that the particular accessions of these ancestral species that were studied were not directly involved in the hybridization events that created these hybrids, since they have similar but not identical cpDNA restriction fragments. Using inter-simple sequence repeat markers that amplified from nuclear genomic DNA, a set of samples including pummelos, citrons, mandarins, sour oranges $(C$. aurantium $\mathrm{L}$.), and 'Samuyao' papeda ( $C$. micrantha Wester) were tested as possible parents of lemons. Sour orange and citron together had all nuclear and chloroplast fragments found in lemon and are therefore proposed to be the maternal and paternal parents, respectively, of many commercial lemon cultivars, including 'Lisbon', 'Eureka', 'Villafranca', and 'Monachello'.
\end{abstract}

Although citrus (Citrus sp.) fruit are the most widely cultivated fruit in the world, the evolutionary origin of many of the commercially important classes including oranges, lemons, and grapefruit remains unclear. It has been extremely difficult to develop improved cultivars in these taxa by hybridization-selection methods, a problem usually attributed to high heterozygosity caused by interspecific hybridization (Roose et al., 1995). Using different methods, several studies have suggested that hybridization among three ancestral species-C. medica, C. maxima, and C. reticulata (Barrett and Rhodes, 1976; Scora, 1975) - produced many other cultivated citrus genotypes including oranges $(C$. sinensis), lemons (C. limon), rough lemons (C. jambhiri), and sweet lemons ( $C$. limetta Risso). Since Citrus was domesticated more than 2000 years ago in areas that have since been extensively developed for agriculture (Swingle and Reece, 1967; Webber et al., 1967), it is also quite possible that some wild ancestors have become extinct. If they are still extant (by vegetative or apomictic reproduction), it should be possible to identify the precise parental genotypes of a hybrid using a sufficient number of nuclear and uniparentally inherited DNA markers (Bowers et al., 1999), and perhaps resynthesize these hybrid taxa.

Although lemon was accepted as a species by the two most widely used taxonomic systems (Swingle and Reece, 1967; Tanaka, 1977), many studies have suggested that lemon is likely

Received for publication 23 Mar. 2000. Accepted for publication 6 Nov. 2000. This paper is a portion of a MS thesis submitted by O.G. We thank Claire Federici, Robert Krueger, Rainer Scora, Mark Springer, and Richard Whitkus for advice and assistance and the Minister of Agriculture and Rural Affairs of Turkey for financial support. The cost of publishing this paper was defrayed in part by the payment of page charges. Under postal regulations, this paper therefore must be hereby marked advertisement solely to indicate this fact.

${ }^{1}$ Current address: Alata Bahce Kulturleri Arastirma Enstitusu, Erdemli-ICEL, 33740 Turkey.

${ }^{2}$ Corresponding author: e-mail: roose @ citrus.ucr.edu. to be of hybrid origin (Barrett and Rhodes, 1976; Federici et al., 1998; Green et al., 1986; Handa et al., 1986; Herrero et al., 1996; Malik et al., 1974; Torres et al., 1978). Malik et al. (1974) found that lemon is a complex hybrid having similarities with citron, lime, rough lemon, and 'Rangpur' lime. It has not been possible to obtain acceptable lemon-like fruit by either hybridization within $C$. limon or crossing with several other species (Malik et al., 1974), perhaps because the correct parental genotypes were not crossed. Crosses between lemon and other Citrus sp. produce hybrids with low economic values (Russo and Tribulato, 1986: cited in Deng et al., 1995).

We previously studied genetic diversity of lemons and some closely related Citrus taxa using inter-simple sequence repeat (ISSR) markers, isozymes, and microsatellites, and found that 1) almost all commercial lemon cultivars originated by mutation from one (or very few) ancestral plants and are genotypically identical for the markers surveyed, 2) citron or its close relatives contributed the largest part of the lemon genome, and 3) unique pummelo and mandarin markers were detected in the lemon genome (Gulsen, 1999). Here we report a study of relationships between lemons and other taxa based on chloroplast DNA (cpDNA) and attempt to identify the parents of lemons and certain other suspected hybrids.

Organelle DNAs, both chloroplast and mitochondrial, are usually maternally inherited in higher plants (Corriveau and Coleman, 1988) including Citrus (Green et al., 1986, Yamamoto et al., 1993), thereby allowing identification of the maternal parent of a hybrid. Polymorphisms in organelle DNA can be used over a wide range of taxonomic levels (Crawford, 1990; Palmer et al., 1988; Soltis et al., 1992). We studied cpDNA restriction fragment length polymorphisms (cpRFLPs), a technique that has been applied successfully in several studies (Cipriani et al., 1998; Nicolosi et al., 2000; Parducci and Szmidt, 1999; Perez de la Rosa et al., 1995). The method involves polymerase chain reaction 
(PCR) amplification of coding or noncoding cpDNA, using a pair of primers specific for each locus, digestion of amplified products with restriction endonucleases, and separation of restriction fragments on gels. Polymorphism occurs due to insertions, deletions, or base changes, usually within noncoding cpDNA sites. To further test parentage of lemon, 15 samples, including lemons, citrons, pummelos, sour oranges and one papeda accession were evaluated for nuclear ISSR markers.

\section{Materials and Methods}

Plant materials. For the cpDNA study, a total of 30 accessions including nine lemons (Citrus limon), three citrons $(C$. medica), three pummelos (C. maxima), 12 accessions of Citrus from 12 species (Tanaka, 1977), and three accessions from three related genera (Table 1) were sampled from the Citrus Variety Collection (CVC) at the University of California, Riverside (UCR). The nine lemons selected had distinct genotypes for nuclear genome markers (Gulsen, 1999). Because many lemons are genetically identical or nearly so, these nine accessions are representative of the genetic diversity among 45 commercially and genetically important lemons from all over the world, including 'Eureka', 'Lisbon', 'Femminello', 'Monachello', 'Villafranca', and the other true lemons. The cpDNA study reported herein also included suspected hybrid taxa such as rough lemons, sweet lemons, and 'Hangleson' Rangpur lime (Barrett and Rhodes, 1976; Scora, 1988); possible ancient or ancestral types such as 'Diamante' citron, 'Standard' sour orange, and several pummelos, $C$. sunki Hort. ex. Tan., C. clementina Hort. ex. Y. Tan. and members of three related genera (Federici et al., 1998; Scora, personal communication; Swingle and Reece, 1967). We also studied ISSR markers of 15 Citrus taxa (Table 1), including two lemons that represent 48 lemons of our previous study (Gulsen, 1999), and 13 apparently ancient putative parents (Swingle and Reece, 1967) including two citrons, three pummelos, two sour oranges, four mandarins, 'Tachibana' orange $[C$. tachibana (Mak.) Tan.], and one papeda accession.

DNA EXTRACTION. Total DNA for the cpDNA and ISSR studies

Table 1. Accessions studied for cpDNA RFLP and ISSR markers, identified by Tanaka (1977) species name, and CRC identification number (Citrus Research Center, University of Calif., Riverside).

\begin{tabular}{|c|c|c|c|c|}
\hline \multirow[b]{2}{*}{ Species } & \multirow{2}{*}{$\begin{array}{c}\text { CRC } \\
\text { no. }\end{array}$} & \multirow[b]{2}{*}{ Common/cultivar name } & \multicolumn{2}{|c|}{ Markers studied } \\
\hline & & & cpRFLP & ISSR \\
\hline C. amblycarpa Ochse & 2485 & 'Nasnaran' mandarin & & $\mathrm{X}$ \\
\hline C. aurantifolia (Christm.) Swing. & 1710 & 'Mexican' lime & $\mathrm{X}$ & \\
\hline C. aurantium $\mathrm{L}$. & 0628 & 'Standard' sour orange & $\mathrm{X}$ & $\mathrm{X}$ \\
\hline C. aurantium $\mathrm{L}$. & 2438 & 'Tunisian' sour orange & & $\mathrm{X}$ \\
\hline C. bergamia Risso and Poit. & 2881 & Bergamot orange & $\mathrm{X}$ & \\
\hline C. indica Tan. & 3163 & Indian wild orange & $\mathrm{X}$ & \\
\hline C. halimii B. C. Stone & 3900 & Unnamed & $\mathrm{X}$ & \\
\hline C. jambhiri Lush. & 3060 & Unnamed rough lemon & $\mathrm{X}$ & \\
\hline C. limetta Risso & 3093 & Iran sweet lemon & $X$ & \\
\hline C. limon (L.) Burm. f. & 3388 & 'Femminello Ovale' lemon & $\mathrm{X}$ & \\
\hline C. limon (L.) Burm. f. & 0280 & 'Villafranca' lemon & $X$ & $\mathrm{X}$ \\
\hline C. limon (L.) Burm. f. & 3007 & 'Allen Variegated Eureka' lemon & $\mathrm{X}$ & \\
\hline C. limon (L.) Burm. f. & 3885 & Iran local lemon & $\mathrm{X}$ & \\
\hline C. limon (L.) Burm. f. & 3590 & 'Berna' lemon & $\mathrm{X}$ & \\
\hline C. limon (L.) Burm. f. & 3500 & 'Femminello Lisbon' lemon & $X$ & \\
\hline C. limon (L.) Burm. f. & 3591 & ‘Corpaci’ lemon & $\mathrm{X}$ & $\mathrm{X}$ \\
\hline C. limon (L.) Burm. f. & 3593 & 'Interdonato' lemon & $\mathrm{X}$ & \\
\hline C. limon (L.) Burm. f. & 3737 & 'Improved Meyer’ lemon & $\mathrm{X}$ & \\
\hline C. limonia Osbeck & 3932 & 'Hangleson’ Rangpur lime & $\mathrm{X}$ & \\
\hline C. maxima (Burm.) Merrill & 2240 & 'Siamese Acidless' pummelo & $X$ & \\
\hline C. maxima (Burm.) Merrill & 2355 & Unnamed Thai pummelo & $\mathrm{X}$ & $\mathrm{X}$ \\
\hline C. maxima (Burm.) Merrill & 3926 & 'Kao Phuang’ pummelo & & $\mathrm{X}$ \\
\hline C. maxima (Burm.) Merrill & 2348 & 'Pin Shan Kong Yau' pummelo & & $X$ \\
\hline C. maxima (Burm.) Merrill & 2340 & Unnamed pummelo & $\mathrm{X}$ & \\
\hline C. medica $\mathrm{L}$. & 3768 & 'Buddha`s Hand' citron & $\mathrm{X}$ & $\mathrm{X}$ \\
\hline C. medica $\mathrm{L}$. & 3891 & 'Ethrog' citron & $\mathrm{X}$ & \\
\hline C. medica $\mathrm{L}$. & 3523 & 'Diamante' citron & $\mathrm{X}$ & $\mathrm{X}$ \\
\hline C. micrantha Wester & 3605 & ‘Samuyao’ papeda & & $\mathrm{X}$ \\
\hline C. nippokoreana Tan. & 3228 & 'Korai tachibana' mandarin & & $\mathrm{X}$ \\
\hline C. reticulata Blanco & 3849 & 'Ponkan' mandarin & $\mathrm{X}$ & $\mathrm{X}$ \\
\hline C. clementina Hort. ex. Y. Tan. & 0279 & 'Clementine' mandarin & $\mathrm{X}$ & \\
\hline C. sinensis (L.) Osbeck & 2750 & 'Olinda Valencia' orange & $\mathrm{X}$ & \\
\hline C. sunki Hort. ex. Tan. & 3143 & 'Sunki’ mandarin & $X$ & $\mathrm{X}$ \\
\hline C. tachibana (Mak.) Tan. & 3150 & 'Tachibana' orange & & $\mathrm{X}$ \\
\hline Eremocitrus glauca (Lindl.) Swing. & 3463 & Australian desert lime & $\mathrm{X}$ & \\
\hline Fortunella polyandra (Ridl.) Tan. & 3901 & Malayan kumquat & $\mathrm{X}$ & \\
\hline Microcitrus australis (Planch.) Swing. & 3666 & Australian round lime & $\mathrm{X}$ & \\
\hline
\end{tabular}


was extracted from fresh leaves according to (Webb and Knapp (1990) modified as described by Fang et al., 1997. DNA pellets were redissolved in $250 \mu \mathrm{L}$ of TE $(10 \mathrm{~mm}$ Tris- $\mathrm{HCl}, 0.1 \mathrm{~mm}$ EDTA, $\mathrm{pH}$ 8.0).

Chloroplast dna analysis. Four universal chloroplast primer pairs anchored at tRNA coding regions and tested previously for a range of plant species (Demesure et al., 1995) were used to amplify coding and noncoding regions. Each $25 \mu \mathrm{L}$ amplification reaction consisted of $10 \mathrm{~mm}$ Tris- $\mathrm{HCl}$ ( $\mathrm{pH} 9.0), 5 \mathrm{~mm} \mathrm{MgCl}_{2}, 0.32$ mM each of dNTP, $0.5 \mu \mathrm{M}$ of each primer, $20 \mathrm{ng}$ of template, and 1 unit of Taq polymerase. For primers of the trnH-trnK pair, $\mathrm{MgCl}_{2}$ concentration was reduced to $3.5 \mathrm{~mm}$. Cycling parameters were; 1 cycle of $5 \mathrm{~min}$ at $94{ }^{\circ} \mathrm{C}, 34$ cycles of $1 \mathrm{~min}$ at $94{ }^{\circ} \mathrm{C}, 1 \mathrm{~min}$ at $55^{\circ} \mathrm{C}, 2.5 \mathrm{~min}$ at $72{ }^{\circ} \mathrm{C}$, and for extension, 1 cycle of $10 \mathrm{~min}$ at $72{ }^{\circ} \mathrm{C}$. Reactions were overlaid with $50 \mu \mathrm{L}$ of mineral oil during amplification. Amplified products were digested with the following enzymes: trnH-trnK products were digested with $R s a$ I and Hae III; trnK-trnK products were digested with Dra I and Mbo I; trnD-trnT were digested with Hae III, Rsa I and Mbo I; and trnStrnT products were digested with Hae III and Rsa I. The digested products were separated on $6 \%$ nondenaturing polyacrylamide gels and detected by silver staining (Fang et al., 1997).

ISSR ANALYSIS. ISSR-PCR amplification, electrophoresis, and silver staining were according to Fang et al. (1997) except that 15 $\mu \mathrm{L}$ PCR reactions were used. The 8 primers used were $\mathrm{BDB}(\mathrm{CA})_{7} \mathrm{C}, \mathrm{DBDA}(\mathrm{CA})_{7}, \mathrm{HVH}(\mathrm{CA})_{7} \mathrm{~T},(\mathrm{GA})_{8} \mathrm{YA},(\mathrm{GA})_{8} \mathrm{YG}$, VHVG(TG) $)_{7}, \mathrm{HVH}(\mathrm{TCC})_{7}$, and (TCC $)_{5} \mathrm{RY}$.

DATA ANALYSIS. In the chloroplast DNA study, each restriction fragment was scored as present or absent and data were analyzed using the PAUP package version 4.0 (Swofford, 1998). Phylogenetic reconstruction was based on the maximum parsimony method, carried out by a heuristic search. Only one input order was used, and tree-bisection reconnection was used for branch swapping. Stepwise addition, MULTIPARS was used. Bootstrap and strict consensus trees were constructed with 500 replicates for the bootstrap analysis. To test the consistency of two phylogeny methods with the same data set, a similarity matrix based on Dice's coefficient (1945) was produced using only the present bands and an unweighted pair group method arithmetic average (UPGMA) tree was constructed with NTSYS-PC version 1.80 software package (Rohlf, 1993). For the ISSR study, the bands were scored as present or absent, and the data matrix was analyzed manually to determine whether all bands present in a suspected hybrid were present in various pairs of putative parents.

\section{Results and Discussion}

The number of digested products ranged from 2 (trnH-trnK with endonucleases Rsa I and Hae III, trnD-trnT with endonuclease Rsa I, and trnS-trnT with endonuclease Hae III) to 6 (trnK-
trnK with endonuclease $M b o$ I). Of 103 fragments scored, 97 were polymorphic. The total length of the amplified region was 7950 base pairs (bp) (Table 2), slightly longer than $7570 \mathrm{bp}$ amplified with these primers in oak (Quercus rober L.) (Demesure et al., 1995). Analysis of fragments on high-resolution polyacrylamide gels allowed detection of polymorphisms that would not have been detected on most agarose gels.

The bootstrap and strict consensus trees had similar branching patterns (Figs. 1 and 2). According to these trees, there are three main branches of the in-group. The first branch includes all lemons, pummelos, 'Olinda Valencia' orange, sweet lemon, Bergamot orange, and 'Standard' sour orange. The second branch contains mandarins, rough lemon, 'Hangleson' Rangpur lime, and 'Mexican' lime. The third group includes citrons, $C$. indica Tan., Microcitrus australis Planch. and Eremocitrus glauca (Lindl.) Swing. Nuclear genome RFLPs clustered citron and $C$. indica, but these taxa were quite distant from $M$. australis, and $E$. glauca (Federici et al., 1998). Fortunella polyandra (Ridl.) Tan. and $C$. halimii B.C. Stone had totally different cpRFLP patterns from the other taxa analyzed. Perhaps $F$. polyandra and $C$. halimii, both found in the Malaysian Peninsula, were more isolated from Citrus than the Australian taxa, M. australis and E. glauca. In the study of Nicolosi et al. (2000), cpDNA indicated that Fortunella, Microcitrus and Eremocitrus were more closely related to other Citrus taxa than were citron and $C$. indica.

The chloroplast data clustered all lemons with the three pummelo ( $C$. maxima) accessions tested, but trees based on nuclear genome DNA markers (ISSRs, isozymes, SSRs, and RFLPs) clustered lemons with citrons ( $C$. medica) (Federici et al., 1998; Gulsen, 1999). In the cpDNA tree, the bootstrap value for the lemon-pummelo cluster was very high $(90 \%)$. In addition to lemons, 'Olinda Valencia' orange (C. sinensis), 'Standard Sour' orange ( $C$. aurantium), and Bergamot orange ( $C$. bergamia) were clustered with pummelos. No differences were observed between the eight lemon accessions and the one sour orange accession, 'Standard', characterized as "typical sour orange" in notes on the Citrus Variety Collection (Fig. 3). Lemon cpDNA was identical to that of sour orange in a similar cpRFLP study (Nicolosi et al., 2000)

In the ISSR study, no bands unique to lemons were detected. All 64 lemon bands were found in either citrons or sour oranges (Table 3). No other pair of taxa studied could account for all of the ISSR bands and cpDNA restriction fragments of lemon. Nicolosi et al. (2000) found that sour orange and citron could account for all but two nuclear markers of lemon. The exact match in our study may occur because we studied different citron cultivars than Nicolosi et al. Of 35 ISSR bands of pummelos, 25 were found in lemons (Gulsen, 1999). This suggests that a pummelo, a close relative, or a pummelo hybrid was a direct or indirect ancestor of lemon.

Table 2. Pairs of cpDNA primers and PCR product sizes in Citrus and Quercus (oak).

\begin{tabular}{lcc}
\hline \hline Primer & \multicolumn{1}{c}{ PCR product size (bp) } \\
\cline { 2 - 2 } pair & Citrus & Quercus $^{2}$ \\
\hline trnH [tRNA-His (GUG)]-trnK [tRNA-Lys (UUU)] exon 1 & 2000 & 1690 \\
trnK [tRNA-Lys (UUU)] exon 1-trnK [tRNA-Lys (UUU)] exon 2 & 2800 & 2580 \\
trnD [tRNA-Asp (GUC)]-trnT [tRNA-Thr (GGU)] & 1750 & 1800 \\
trnS [tRNA-Ser (GGA)]-trnT [tRNA-Thr (UGU)] & 1400 & 1500 \\
TOTAL bp & 7950 & 7570 \\
\hline
\end{tabular}

${ }^{\mathrm{z}}$ Demesure et al., 1995. 
The literature suggests that the best candidate for the maternal parent of lemon is sour orange because of their similarities in mitochondrial DNA (Yamamoto et al., 1993), chloroplast DNA (Green et al., 1986; Nicolosi et al., 2000), and isozyme patterns (Torres et al., 1978). Sour orange has been suggested to be a pummelo-mandarin hybrid (Green et al., 1986; Nicolosi et al., 2000; Scora, 1975 and 1988; Swingle and Reece, 1967; Yamamoto et al., 1993). Isozyme patterns of SkDH, MDH, IDH, and GOT of lemons, citrons, pummelos, and sour orange are consistent with this possible hybridization event (Gulsen, 1999), as are patterns of Got-1 Got-2, Pgi-1, Pgm, and HK (Torres et al., 1978 and 1982). Sour orange and lemons have identical mtDNA and cpDNA RFLPs (Yamamoto et al., 1993). Biochemical similarities between lime [C. aurantifolia (Christm.) Swingle] and lemon led Scora (1975) to suggest that lime may be a parent of lemon. However, this similarity may also result from both lemon and lime having mandarin ancestry (Scora, 1975). In addition to bands unique to citron and pummelo, mandarin-specific ISSR bands were detected in lemons (Gulsen, 1999). This supports the hypothesis that sour orange is the maternal parent of lemons. Sour orange produces about $15 \%$ zygotic (nonapomictic) seedlings (Torres, 1938) and therefore could be the maternal parent of lemon.

There was no cpRFLP diversity among the nine lemons which had shown ISSR, isozyme, and SSR diversity, except for 'Improved Meyer' lemon, whose chloroplast patterns are more similar to those of 'Valencia' orange (C. sinensis). Probably, 'Improved Meyer' lemon has a different pummelo as its female grandparent than lemon. It has been suggested that it is a sweet orange hybrid (Scora, 1975).

All tested citrons had the same chloroplast patterns (Fig. 3). Some resemblance was found between citron and $C$. indica, $M$. australis, and E. glauca for the tested four loci, with bootstrap

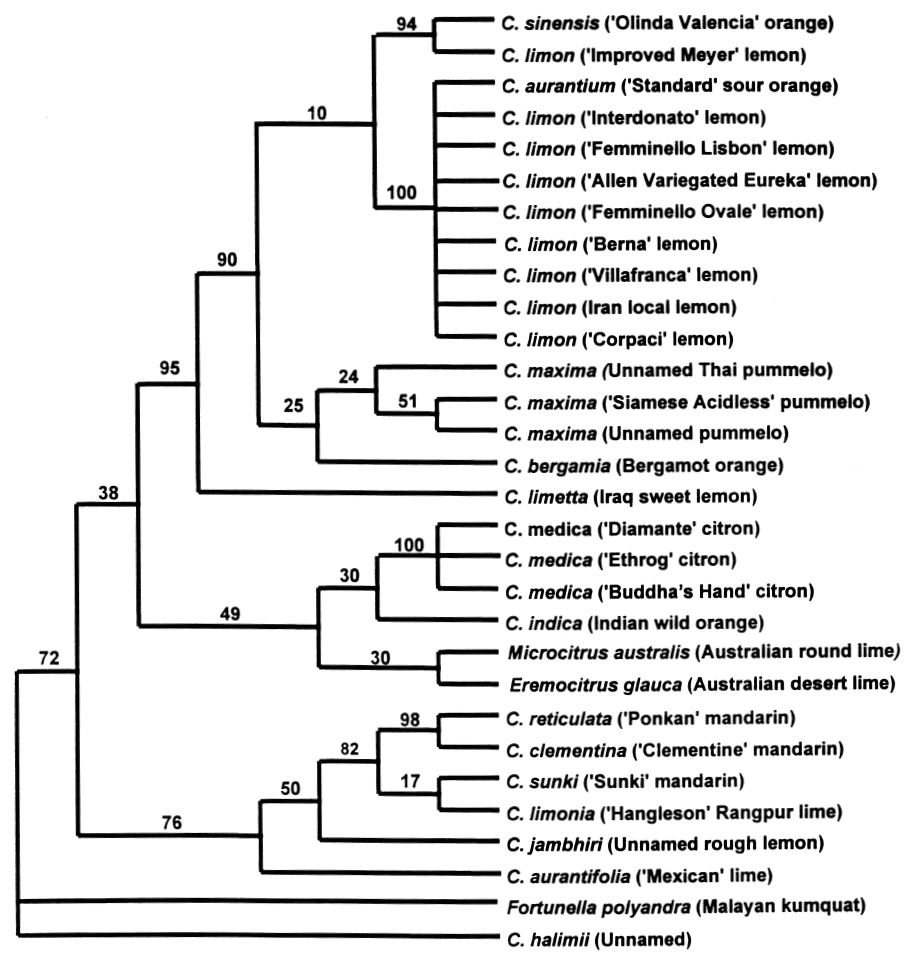

Fig. 1. Maximum parsimony dendrogram of 27 Citrus accessions and three related genera based on analysis of 97 polymorphic cpDNA restriction fragments from 4 cpDNA sequences. Bootstrap values shown based on 500 resamplings. values of almost 50\%. Almost all citron ISSR bands (which are based on nuclear genomic DNA) were found in lemons, but there was a low similarity value, 0.4 , between citron and lemon cpDNA restriction fragments. Because cpDNA in Citrus is maternally inherited (Green et al., 1986; Yamamoto et al., 1993), citron cannot be the female parent of lemon. However citron, or a close relative could be the male parent of all lemons, contributing $50 \%$ of the nuclear genome of lemon.

CpDNA patterns clustered 'Hangleson' Rangpur lime $(C$. limonia), rough lemon ( $C$. jambhiri), and 'Mexican' lime $(C$. aurantifolia) with mandarins at a high bootstrap value $(76 \%)$. Nicolosi et al. (2000) found that cpDNA clustered 'Mexican' lime with several species (including $C$. micrantha) whose cpDNA we did not study. Since nuclear ISSR marker data clustered 'Hangleson' Rangpur lime and rough lemon with citrons and lemons, it seems possible that these taxa are mandarin $\mathrm{x}$ citron hybrids. Some diversity was also found within mandarins. Citrus sunki was more similar to 'Hangleson' Rangpur than to 'Clementine' or 'Ponkan' mandarins.

In order to test whether different methods of phylogenetic analysis give similar results with this data set, a distance method (UPGMA) was employed. The phylogenetic trees produced by the distance and parsimony methods were very similar.

Our results are consistent with the hypothesis that citron $(C$. medica), pummelo ( $C$. maxima), and mandarin ( $C$. reticulata) represent true (nonhybrid) species of Citrus. Although these species are freely interfertile, they probably evolved with some geographic isolation (Roose et al., 1995). CpDNA restriction fragments of these three putative ancestral types are distinct from each other, having similarity values of around 0.5 . Since cpDNAs of land plants evolve more slowly than nuclear and mitochondrial

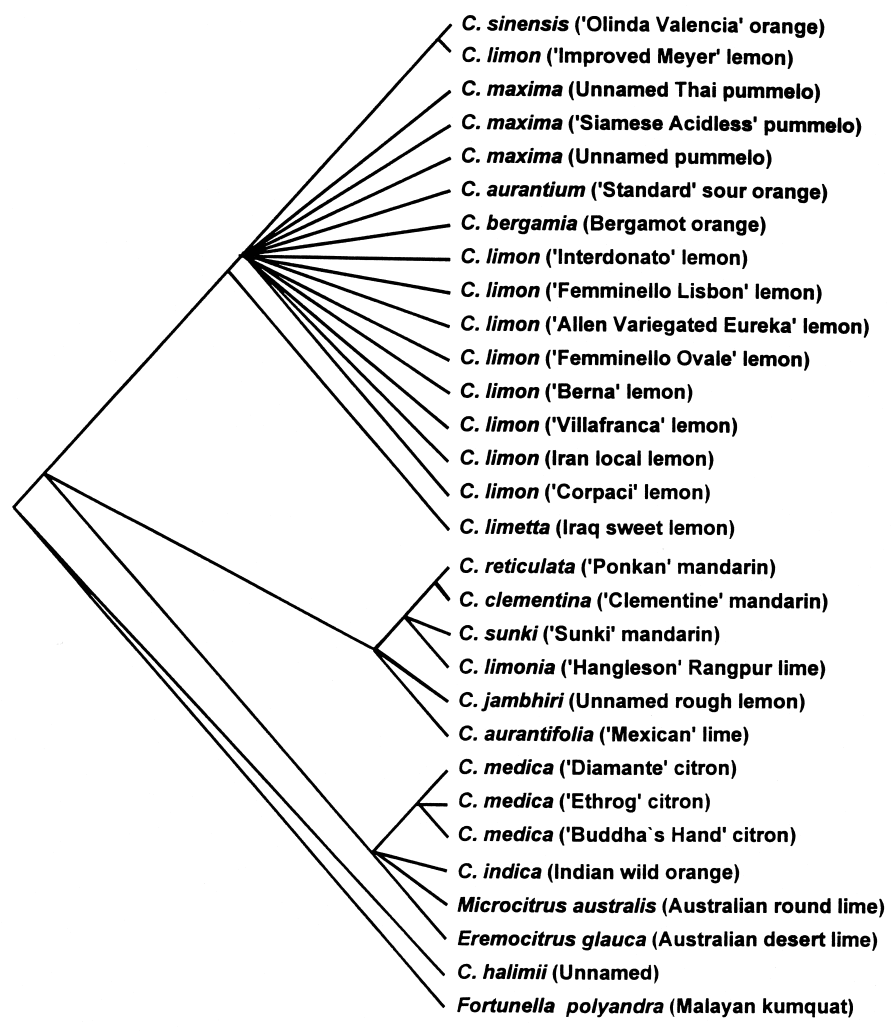

Fig. 2. Strict consensus tree of 27 Citrus accessions and three related genera based on analysis of 97 polymorphic cpDNA restriction fragments from 4 cpDNA sequences. Consensus based on 500 bootstrap resamplings. 


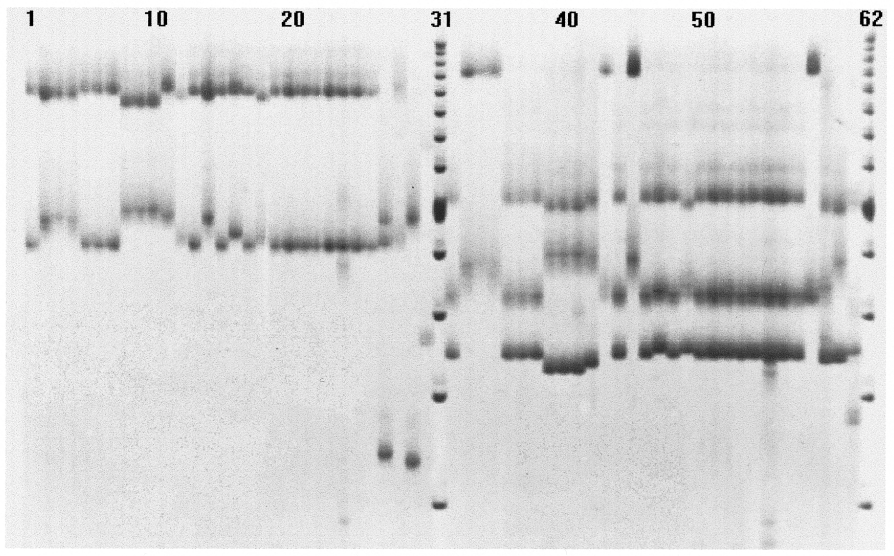

Fig. 3. CpDNA restriction fragments of 27 Citrus accessions and three related genera, following amplification with primers $\operatorname{trn} D$-trnT and digestion with restriction enzymes Rsa I (lanes 1-30) and Hae III (lanes 32-61). The lane order is as follows: lanes 31 and 62 are DNA markers at $100 \mathrm{bp}$ intervals, the most rapidly migrating band is $300 \mathrm{bp}$; 1 and 32) 'Olinda Valencia' orange, 2 and 33) 'Ponkan' mandarin, 3 and 34) 'Sunki' mandarin, 4 and 35) 'Clementine' mandarin, 5 and 36) unnamed Thai pummelo, 6 and 37) 'Siamese Acidless' pummelo, 7 and 38) unnamed pummelo, 8 and 39) 'Buddha`s Hand' citron, 9 and 40) 'Ethrog' citron, 10 and 41) 'Diamante' citron, 11 and 42) Indian wild orange, 12 and 43) unnamed rough lemon, 13 and 44) 'Standard' sour orange, 14 and 45) 'Hangleson' Rangpur lime, 15 and 46) 'Improved Meyer' lemon, 16 and 47) Iran sweet lemon, 17 and 48) Bergamot orange, 18 and 49) 'Mexican' lime, 19 and 50) 'Interdonato' lemon, 20 and 51) 'Femminello Lisbon' lemon, 21 and 52) 'Allen Variegated Eureka' lemon, 22 and 53) 'Femminello Ovale' lemon, 23 and 54) 'Berna' lemon, 24 and 55) 'Villafranca' lemon, 25 and 56) Iran local lemon, 26 and 57) 'Corpaci' lemon, 27 and 58) Malayan kumquat, 28 and 59) Australian desert lime, 29 and 60) C. halimii, 30 and 61) Australian round lime.

Table 3. Phenotypes of lemons and 13 putative parents for 64 ISSR bands amplified with eight different primers.

\begin{tabular}{ll}
\hline \hline Accession & ISSR bands scored \\
\hline C. limon 'Villafranca' lemon & 1111111111111111111111111111111111111111111111111111111111111111 \\
C. limon 'Corpaci' lemon & 111111111111111111111111111111111111111111111111111111111111 \\
C. medica 'Diamante' citron & 0110001111110000101011010011010010010100001011000111100100101110 \\
C. medica 'Buddha's Hand' citron & 0110010111110001101011010011010010010110000011000111100100101110 \\
C. aurantium 'Standard' sour orange & 1001111000001110011101101101111101101001111100111110111111010001 \\
C. aurantium 'Tunisian' sour orange & 1001111000001110010101101101111101101001111100111110111111010001 \\
C. maxima 'Kao Phuang' pummelo & 1000001001101010000100000000010000011000010000011010101000000000 \\
C. maxima (Unnamed Thai) pummelo & 0000100001000010000000000000010000011001010000010010001000000000 \\
C. maxima 'Pin Shan Kong Yau' pummelo & 1000001001101010001100000001010000111000010010011010001000000000 \\
C. tachibana 'Tachibana' orange & 0001000000001010001111101000000101001000001000101010000001000000 \\
C. reticulata 'Ponkan' mandarin & 0001110100101000010100101000100101001000001100011010111001000000 \\
C. sunki 'Sunki' mandarin & 0001110100001010010101101000100101001000001100011110110101000000 \\
C. amblycarpa 'Nasnaran' mandarin & 0000100100001000010101101000100101001000001100111010111001100000 \\
C. nippokoreana 'Korai tachibana' mandarin & 0010100000101110000111000000110000001100001000011010101101000000 \\
C. micrantha 'Samuyao' papeda & 1000100000010010000001000000000000001000000000000000001000100000 \\
\hline
\end{tabular}

DNA (Clegg et al., 1994), this level of divergence supports the three species concept. We studied cpDNA regions which are believed to be less conserved, and therefore this level of divergence is unlikely to apply to the entire chloroplast genome. The cpDNAs of many Citrus taxa believed to be hybrids were very similar to those of these ancestral taxa. C. halimii clearly represents a divergent lineage as has been suggested previously (Stone et al., 1973).

Combining data on cpRFLP patterns with nuclear marker data such as ISSRs or SSRs provides a powerful approach for inferring parentage of natural hybrids. Similar methods can be applied to other problematic taxa in Citrus, including orange. Identification of parental taxa may aid breeders in developing improved cultivars by hybridization.

\section{Literature Cited}

Barrett, H.C. and A.M. Rhodes. 1976. A numerical taxonomic study of affinity relationships in cultivated Citrus and its close relatives. Systematic Bot. 1:105-136.

Bowers, J., J. Boursiquot, P. This, K. Chu, H. Johansson, and C. Meredith. 1999. Historical genetics: The parentage of Chardonnay, Gamay, and other wine grapes of northeastern France. Science 285:1562-1565.

Cipriani, G., R. Testolin, and R. Gardner. 1998. Restriction-site variation of PCR-amplified chloroplast DNA regions and its implication for the evolution and taxonomy of Actinidia. Theor. Appl. Genet. 96:389396.

Clegg, M.T., B.S. Gaut, G.H. Learn, and B.R. Morton. 1994. Rates and patterns of chloroplast DNA evolution. Proc. Natl. Acad. Sci. USA 91:6795-6801.

Corriveau, J.L. and A.W. Coleman. 1988. Rapid screening method to detect potential biparental inheritance of plastid DNA and results over 200 angiosperm species. Amer. J. Bot. 75:1443-1458.

Crawford, D.J. 1990. Plant molecular systematics: Macromolecular approaches. Wiley, New York.

Demesure, B., N. Sodzi, and R.J. Petit. 1995. A set of universal primers for amplification of polymorphic non-coding regions of mitochondrial and chloroplast DNA in plants. Mol. Ecol. 4:129-131.

Deng, Z.N., A. Gentile, E. Nicolosi, A. Vardi, and E. Tribulato. 1995. Identification of in vivo and in vitro lemon mutants by RAPD markers. J. Hort. Sci. 7:117-125.

Dice, L.R. 1945. Measures of the amount of ecologic association between species. Ecology 26:297-302.

Fang, D.Q., M.L. Roose, R.R. Krueger, and C.T. Federici. 1997. Fingerprinting trifoliate orange germ plasm accessions with isozymes, RFLPs, and inter-simple sequence repeat markers. Theor. Appl. Genet. 95:211219.

Federici, C.T., D.Q. Fang, R.W. Scora, and M.L. Roose. 1998. Phylogenetic relationships within the genus Citrus (Rutaceae) and related genera as revealed by RFLP and RAPD analysis. Theor. Appl. Genet. 96:812-822.

Green, R.M., A. Vardi, and E. Galun. 1986. The plastome of Citrus. Physical map, variation among Citrus cultivars and species and comparison with related genera. Theor. Appl. Genet. 72:170-177.

Gulsen, O. 1999. Lemons: Their diversity, relationships with some selected Citrus genotypes, and parentage. MS Thesis, Dept. of Botany and Plant Sciences, Univ. of Calif., Riverside.

Handa, T., Y. Ishizawa, and C. Oogaki. 1986. Phylogenic study of 
Fraction 1 protein in the genus Citrus and its close related genera. Jpn. J. Genet. 61:15-24.

Herrero, R., M.J. Asins, E.A. Carbonell, and L. Navarro. 1996. Genetic diversity in the orange subfamily Aurantioideae. I. Intraspecies and intragenus genetic variability. Theor. Appl. Genet. 92:599-609.

Malik, M.N., R.W. Scora, and R.K. Soost. 1974. Studies on the origin of the lemon. Hilgardia 42:361-382.

Nicolosi, E., Z.N. Deng, A. Gentile, S. La Malfa, G. Continella, and E. Tribulato. 2000. Citrus phylogeny and genetic origin of important species as investigated by molecular markers. Theor. Appl. Genet. 100:1155-1166.

Palmer, J.D., R.K. Jansen, H.J. Michaels, M.W. Chase, and J.R. Manhart. 1988. Chloroplast DNA variation and plant phylogeny. Ann. Missouri Bot. Gard. 75:1180-1206.

Parducci, L. and A.E. Szmidt. 1999. PCR-RFLP analysis of cpDNA in the genus Abies. Theor. Appl. Genet. 98:802-808.

Perez de la Rosa, J.P., S.A. Harris, and A. Farjon. 1995. Noncoding chloroplast DNA variation in Mexican pines. Theor. Appl. Genet. 91:1101-1106.

Rohlf, F.J. 1993. NTSYS-PC, numerical taxonomy and multivariate analysis system. Version 1.80. Exeter Software, Setauket, N.Y.

Roose, M.L., R.K. Soost, and J.W. Cameron. 1995. Citrus, p. 443-448. In: J. Smartt and N.W. Simmonds (eds.). Evolution of crop plants. Longman, Harlow, United Kingdom.

Russo, F. and E. Tribulato. 1986. La ricerca e il miglioramento genetico degli agrumi. II Recent Contributo della Ricerca allo Sviluppo dell ${ }^{\circ}$ Agrumicoltura Italiana. p. 23-29.

Scora, R.W. 1975. On the history and origin of Citrus. Bul. Torrey Bot. Club 102:369-375.

Scora, R.W. 1988. Biochemistry, taxonomy and evolution of modern cultivated Citrus, p. 277-289. In: R. Goren and K. Mendel (eds.). Proc. 6th Intl. Citrus Congr. vol. 1. Margraf Publ., Weikersheim, Germany.
Soltis, D.E., P.S. Soltis, and B.G. Milligan. 1992. Intra-specific chloroplast DNA variation: Systematic and phylogenetic implications, $p$. 117-150. In: P.S. Soltis, D.E. Soltis, and J.J. Doyle (eds.). Molecular systematics of plants. Chapman and Hall, New York.

Stone, B.C., J.B. Lowry, R.W. Scora, and K. Jong. 1973. Citrus halimii: A new species from Malaysia and peninsular Thailand. Biotropica 5:102-110.

Swingle, W.T. and P.C. Reece. 1967. The botany of Citrus and its wild relatives, p. 190-430. In: W. Reuther, H.J. Webber, and L.D. Batchelor (eds.). The citrus industry. vol. 1. Univ. of Calif., Berkeley.

Swofford, D.L. 1998. Phylogenetic analysis using parsimony. Vers. 4.0. Sinauer, Sunderland, Mass.

Tanaka, T. 1977. Fundamental discussion of Citrus classification. Studia Citrologia 14:1-6

Torres, A.M., R.K. Soost, and U. Diedenhofen. 1978. Leaf isozymes as genetic markers in Citrus. Amer. J. Bot. 65:869-881.

Torres, A.M., R.K. Soost, and T. Mau-Lastovicka. 1982. Citrus isozymes; Genetics and distinguishing nucellar from zygotic seedlings. J. Hered. 73:335-339

Torres, J.P. 1938. Results of citrus hybridization in the Philippines. Philipp. J. Agr. 9:161-176.

Webb, D.M. and S.J. Knapp. 1990. DNA extraction from a previously recalcitrant plant genus. Plant Mol. Biol. Rpt. 8:180-185.

Webber, H.J., W. Reuther, and H.W. Lawton. 1967. History and development of the citrus industry, p. 1-39. In: W. Reuther, H.J. Webber, and L.D. Batchelor (eds.). The citrus industry. vol. 1. Univ. of Calif., Berkeley.

Yamamoto, M., S. Kobayashi, Y. Nakamura, and Y. Yamada. 1993. Phylogenic relationships of Citrus revealed by diversity of cytoplasmic genomes, p. 39-46. In: T. Hayashi, M. Omura, and N.S. Scott (eds.). Techniques on gene diagnosis and breeding in fruit trees. Fruit Tree Res. Sta., Okitsu, Japan. 